\title{
THE DAYCOURSE OF PLACE
}

\section{Julie Vallée}

CNRS, UMR Géographie-cités

13 rue du Four, 75006 Paris, France

julie.vallee@parisgeo.cnrs.fr

\begin{abstract}
The present paper aims to contribute to the debate about the temporal relationships between place and health. It explores the notion of 'daycourse of place' echoing the discussion which recently occurred in this journal about the 'lifecourse of place' (Andrews, 2017; Lekkas et al., 2017a, b). When highlighting the importance of time in shaping health within places, most of studies focus either on the trajectories of places over a matter of years or the daily trajectories of people in link with their activity space. However, daily trajectories of places remain a poor cousin in place and health literature. This paper is intended to overcome 'jetlag' which places suffer when they are labelled with frozen attributes over a 24-hour period. It explores the values and feasibility of exploring daily trajectories of places to investigate place effects on health or to design area-based interventions for public health action. More than just a metaphor, the 'daycourse of place' appears to be an inspiring framework to elaborate the importance of daily temporal relationalities for research and action in place-based health inequalities.
\end{abstract}

Keywords. lifecourse; daily mobility; trajectory ; neighbourhood effects ; area-based interventions; rhythm ; temporality; Modifiable Spatiotemporal Unit Problem

Echoing the recent debate about the 'lifecourse of place' published in this journal (Andrews, 2017; Lekkas et al., 2017a, b), this paper discusses the notion of 'daycourse of place' as an inspiring framework to strengthen knowledge about place dynamics and their health geographies. When speaking of lifecourse of place, it makes sense to include various time granularities without limiting long-term trajectories to the order of years: places change over a course of years but also over the course of a day. In their respective papers, Lekkas et al. (2017a, b) and Andrews (2017) have only paid attention to trajectories of places over long periods in the wake of research aiming to reconstruct historical landscapes of health resources (e.g. Moon et al., 2002; Pearce, 2015). The present paper aims to discuss the relevance of adding a daycourse perspective within the lifecourse of place' framework when one aims to align the phases/stages of places and the phases/stages of humans (Andrews, 2017). 


\section{Daily trajectories of places matter when investigating place effects on health}

The daycourse of place would first benefit from being more considered in literature about place effects. A careful reading of the well-known framework proposed by Macintyre et al. (2002) about the five types of local features which might influence health leads us to think that each of these five 'opportunity structures' can be affected by daily variations:

- Physical features of the environment (e.g., quality of air and water) are commonly known to be subject to daily variations. Air pollution changes within hours or even minutes, in connection with industrial pollution and automobile traffic, for example. Among the five types of local features, physical aspects are the most explored within a daycourse perspective (e.g. Nyhan et al., 2016; Park \& Kwan, 2016) probably because sensors covering territories may provide data with high temporal precision.

- Provision of decent, secure and non-hazardous environments (at home, work and play) may also vary during the day. For example, children's outdoor play areas may be safe during the day but unsafe during the night if they are not fitted with public lighting. Some mechanisms through which social ties influence fear of crime likely may also differ from day to night (Boessen et al., 2017).Availability of publicly or privately provided services to support people in their daily lives (e.g., education, transport, street cleaning and lighting, policing, health and welfare services) vary over a 24-hour period. Some temporal components such as the opening and closing times of services and the changing number of potential users (residents and non-residents) could to be productively considered (Neutens et al., 2010).

- Socio-cultural features of a neighbourhood (e.g., norms and values, degree of community integration and networks of community support) differ over the years but also within a single day. Such daily cycles are strongly related to different combinations of resident and nonresident populations (Nuvolati, 2003) and to their behaviour. For example, cigarette consumption can be locally stigmatised or not according to the time of day and depending on the behavioural backgrounds and practices of the different combinations of resident and non-resident populations.

- Finally the reputation of a place may also be subject to variations. Residents and nonresidents, service or amenity planners and providers may change their mind about a place according to the time of the day. For example, some areas perceived as being safe during the day may be seen as risky during the night. Concepts such as a 'high-crime neighbourhood' or 'safe neighbourhood,' may be experienced and perceived completely differently over the course of the day.

Some place attributes can of course remain the same around the clock: this stability should be considered as information in itself. Rather than considering places as necessarily frozen over a $24 \mathrm{~h}$ period, it is thus useful to remove 'clock blinders' and to explicitly 'timestamp' place attributes when exploring place effects in health.

Daily trajectories of place would also benefit from being considered in the context of the emerging literature concerning people's activity spaces and multiple exposures. Following calls to avoid a 'local trap' (Cummins, 2007), and acknowledging studies that show differences in exposure between residential and non-residential destinations, the literature on people's daily trajectories has emerged using travel diaries, go-along methods, GPS, mobile phone data, etc. However, in many studies integrating people's activity space, great precision in people's trajectories does not fit with omission 
of trajectories of places. To take some examples of empirical studies exploring people's activity spaces, but neglecting daily trajectories of places, one can cite those exploring (i) air pollution data aggregated annually (Setton et al., 2008); (ii) density or distance to health services (Vallée et al., 2010), food services (Kestens et al., 2012; Zenk et al., 2011), green spaces (Chaix et al., 2016), tobacco retailers (Shareck et al., 2016) or alcohol outlets (Basta et al., 2010) computed without considering the opening and closing times of these services; (iii) area-level social profile computed only from resident population through census based information (Chum \& O' Campo, 2013; Inagami et al., 2007; Kimbro et al., 2017; Perchoux at al., 2015; Shareck et al., 2014b; Vallée et al., 2011); (iv) incidence of violence aggregated annually (Chum \& O' Campo, 2013). In these empirical studies (my own included), there is a strong discrepancy between the high degree of accuracy in daily trajectories of people and the degree of accuracy in daily trajectories of places, as though place attributes suffer from a kind of 'jetlag' or 'clocklag'.

Some efforts have been made to define erroneous conclusions which can emerge in contextual health studies when one ignores people's daily trajectories and as a result the true causally relevant spatial contexts. It has been conceptually explored by Kwan (2012) with the notion of 'Uncertain Geographic Context Problem' as an extension of Openshaw's 'Modifiable Areal Unit Problem MAUP' (1984), by Shareck et al. (Shareck et al., 2014a) in relation to social health inequalities and by Perchoux et al. in relation to environmental exposure in epidemiology (2013). Some scholars have also highlighted the theoretical importance of considering time and space in tandem (An et al., 2015) and have drawn attention to 'the modifiable spatiotemporal unit problem' to emphasize that "analysis that is spatially detailed but temporally coarse might be just as likely to impair analysis as that which is temporally detailed but spatially coarse" (Martin et al., 2015). However, only few studies have been devoted to quantifying how measures of neighbourhood effects on health can be wrong when neglecting daily trajectories of places. The pollution domain is currently at the forefront. For example, a recent paper (Nyhan et al., 2016) has compared home population exposure to air pollution in New York City (evaluated using a static population distribution) with active population exposure (evaluated both using spatiotemporal pollution levels and population activity patterns from cellular network). Areas of relatively higher population exposures were found to be concentrated in different districts in both scenarios.

One could conclude this first section by saying that contextual health studies should investigate not only the daycourse of individuals and their activity space, but also the social and economic daily trajectories of the places where they live, work and play. Such an approach, inspired from timegeography, may help balance the recent enthusiasm observed in the health literature towards daily trajectories of people with the relative indifference towards the daily trajectories of places and improve measures of place effects on health.

\section{Daily trajectories of places matter when tackling geographic health inequalities}

Besides the relevance of adopting a daycourse perspective of place to explore contextual effects on health, the daycourse perspective is also relevant when one aims to design area-based interventions to tackle health problems which are spatially concentrated and cumulative. Geographic health inequalities are traditionally studied from the spatial concentration of people residing in areas. But, as Martin et al. (2015) expressed, "an important but rarely acknowledged deficiency of census and administrative sources is that they not only relate to a particular date but are primarily based on 
'nighttime' residential location assumptions; in other words, they represent a notional time when all members of the population are at their residential address". Real-time populations estimates (specfically if they are socially informative) can advantageously assist planners and policy-makers when they design area-based intervetions or urban time policies or when they need baseline to conduct experiments and to measure their efficiciency around the clock (Kontokosta \& Johnson, 2017). When adopting a residential time to tackle geographic health inequalities, daytime interventions (such as health promotion campaigns or screening programmes) intended for more socially deprived populations may be ineffective if they are implemented during the day in areas where deprived people are highly concentrated during the night but are absent during the day, and if, inversely, they do not target the areas which deprived people visit during the day without residing there (Vallée, 2017). As shown recently, Paris neighborhoods with similar social composition during the night can differ deeply in their social composition during the day because of socially selective daily trips (Le Roux et al., 2017). Neglecting change in population composition around the clock, conventional area-based interventions may wrongly target areas ('false positives') or wrongly ignore other areas ('false negatives'). A link may be drawn here to the question of the critical representation of targeted groups in targeted areas, i.e. the effectiveness of area-based targeting in reaching priority populations. Surprisingly, the assumption behind critical representation has rarely been empirically tested (Sharpe, 2013). When it was done - for example in England (Tunstall \& Lupton, 2003) it only concerned the number of targeted people residing in the target areas as a percentage of the total number of targeted people in the country (completeness) and the number of targeted people residing in the target areas as a percentage of the total population residing in these target areas (efficiency). It would yet be very interesting to move beyond these residential-based estimates and investigate how critical representation of priority populations within targeted areas change (or do not change) around the clock (Vallée, 2017).

\section{Data and methods to explore daily trajectories of places}

As for the lifecourse of place, a prerequisite for the daycourse approach is having precise temporal information relating to the places concerned (Pearce, 2015). The present section aims to list some sources pertaining to explore the daily trajectories of places.

The first series of data come directly from individuals (Thornton et al., 2011): (i) 'psychometric' data based on surveys of individuals who report and evaluate place attributes; and/or (ii) 'ecometric' data though direct or 'systematic social' observations undertaken by fieldwork auditors who visit places physically or virtually from remote sensing techniques, e.g., the Street View feature in Google Earth, (Bethlehem et al., 2014) to make observations. Although rarely employed, these two traditional methods can be also used to explore the daily variation of places: residents, non-residents or auditors can describe place attributes over the course of a day. In this regard, Ecological Moment Assessment (EMA) Technology (mainly used to monitor temporal and spatial variation of health behaviour and outcomes as reported by participants themselves) could be also used to monitor how people report temporal variation in place attributes around the clock.

The second series of data come from methods for tracking human movements, such as mobile phone database or origin-destination surveys. Mobile phones provide data about space and time location from a very large number of people, but they are poor in terms of giving individual information, 
notably related to social profile. From mobile phone data, it is then possible to derive the number of people located in different areas at different times of the day, but nothing more about a local area's social composition. Origin-destination surveys provides some precise individual data, including social data, but among a more limited number of surveyed people. It is thus possible to aggregate these data to get place attributes (such as area social composition) around the clock, even if small area estimations are impossible because of the large margins-of-errors for small geographies (Kontokosta \& Johnson, 2017; Le Roux et al., 2017). In comparison, traditional census data provide a large amount of social information among the entire population, but are imprecise about space and time trajectories of people (focusing often only on their commuting practices). As things stand at present, one of the best solutions is to use origin-destination surveys, as it was done in the Paris region (France), when one aims to explore change in area social composition around the clock (Le Roux et al., 2017) and to design web mapping tools composition with an interactive daily timeline (e.g. the Mobiliscope - http://mobiliscope.parisgeo.cnrs.fr/, Géographie-cités, 2017).

The third series of data come from external sources. Some of them (commercial data company websites or Google Street View, phone directories etc.) are generally updated yearly. To get place attributes which would be hour-stamped, web scraping is a first alternative: it provides the opportunity to extract information about opening and closing hours of listed services from platform such as Google Map. A second alternative is to make phone calls to get temporal information about a stratified random sample of shops, services and businesses, as it was done in Grenoble, France (Fosset et al., 2016).

The final series of data come from agent-based models that have a great potential to address many space-time analysis challenges as they allow the exploration of the sequential unfolding of agent activities over space and time (An et al., 2015; Kwan, 2013). Complex systems approaches help to more fully realise on-going incursions into explaining how dynamics - processes of change over time impact upon health (Lewis, 2017). In agent-based models, individuals are considered as autonomous and reactive entities (agents), able to perceive and explore places, to modify them and to adapt their (mobility) behaviour when facing unusual conditions (Fosset et al., 2016). Complex space-time data such as peak periods for services or car traffic could be simulated hourly accounting for feedback and dependency between individuals and between individuals and place attributes.

Each of these four data series, which have no pretence of being exhaustive, is in its own way relevant to illustrate a daycourse of place. As underlined by Lekkas et al. (2017b) in their response to Andrews (2017), it is my belief that juxtaposition of data (and the juxtaposition of methods to analyse them) is in and of itself integral to the strengthening of knowledge about neighbourhoods dynamics and their health geographies.

\section{From daily trajectories of places to the 'daycourse of place'}

The three previous sections have underlined the values and feasibility of exploring daily trajectories of places. It is now time to give more depth to the notion 'daycourse of place', in the same way as Andrews (2017) has given depth to the notion 'lifecourse of place' by introducing nonrepresentational theory (NRT) as an alternative approach to space-time statistical models.

First, the daycourse perspective may help to isolate some critical and sensitive periods in which changes in place attributes occur. Daily trajectories of places are not linear: during or around certain 
temporal windows (e.g., lunchtime, beginning or end of working hours, lateness of the evening, etc.), place attributes may change more quickly. Moreover, these critical periods are not necessarily the same across places: temporal signatures of places depend on social, cultural, and economic features (Liu et al., 2015). Between neighbourhoods within a metropolitan region, critical periods with important changes may differ according to whether one looks at areas with nightlife, areas with a high number of families and children going to school, etc. Between countries, critical periods with important daily changes are also not necessarily the same. These specific critical periods should be more explicitly considered when investigating for example how peaks of service congestion impact population health.

Second, days and nights (and their repetition) constitute an important timescale for humans as they impose a biological rhythm. And, it is not to anthropomorphise places to say that daily rhythms constitute an important timescale not only for people but also for places. A link can be drawn here with the notion of urban phenology borrowed by Kontokosta and Johnson (2017) from the biological sciences and defined as "the cyclic and seasonal variations of human behavior in urban environments". Daily rhythms of places are mainly driven by social and political processes. The social determination of domestic, work, and free times impact the socio-temporal signatures of places. Some inclusive day-time areas can then become exclusive for some subgroups of population at night (e.g. children, women). As developed in Lefebvre's Rhythmanalysis (1992), powerful groups imprint rhythms upon places that shape normative rules about behaviors - including health behaviors (Kern, 2016). Temporal signatures of places also result from political decisions. By scheduling public transportation or events in public spaces (markets, festivals etc.), public and private actors may assemble, frame and co-ordinate daily population flows. Such strategies of synchronization play an important part in the production and the control of population in places (Kärrholm, 2009). The 'daycourse of place' framework could then be an inspiring framework to consider more explicitly the social and political rhythms of places over a 24-hour period and their effects on health inequalities.

Third, it is appropriate to specify that the present paper which takes part in the recent debate about the 'lifecourse of place', does not aim to establish a hierarchy between different time granularities. Actually, the daycourse perspective can be seen as completing lifecourse perspective of place in the sense that social processes transforming places over years (e.g. urban regeneration, gentrification) may be rooted in, or reinforced by, some events occurring at some periods of the day (e.g. night time cultural events or morning farmers' markets). These events can - as expressed by Kern (2016) "transform the social space of the neighbourhood in ways that render it unfamiliar and perhaps inaccessible to long-time residents and marginalized community members (...). The reorganization of neighbourhood social life through the creation and privileging of specific temporal landscapes is itself a means of excluding, marginalizing or rendering invisible certain community members and their needs". Daycourse and life course temporalities - as well as some other intermediate temporalities such as weeks or the seasons - would benefit from being included to analyse the lifecourse of place. Applying to places a recent lifecourse visualisation proposed by a father about his daughters sleep (Elliott, 2016), one could for example advantageously explore the 'day rings of place' from concentric circles (with midnight centred at the top - 24 hour clock). Such lifecourse visualisation may help to explore how place attributes change over a 24 -hour period and across the days and ultimately across the years. 
To conclude, the 'daycourse of place' is more than a metaphor: it is an organising framework to question what kind of 'time' is interacting with what kind of 'space' (Crang, 2012). It helps to reveal the social and political processes of within-day change and the critical periods of the day in which places specifically impact health and in which area-based interventions are more effective to reduce health inequalities.

\section{References}

An, L., Tsou, M.-H., Crook, S.E.S., Chun, Y., Spitzberg, B., Gawron, J.M., et al. (2015). Space-Time Analysis: Concepts, Quantitative Methods, and Future Directions. Annals of the Association of American Geographers, 105, 891-914.

Andrews, G.J. (2017). 'Running hot': Placing health in the life and course of the vital city. Soc Sci Med, 175, 209-214.

Basta, L.A., Richmond, T.S., \& Wiebe, D.J. (2010). Neighborhoods, daily activities, and measuring health risks experienced in urban environments. Social Science \& Medicine, 71, 1943-1950.

Bethlehem, J.R., Mackenbach, J.D., Ben-Rebah, M., Compernolle, S., Glonti, K., Bardos, H., et al. (2014). The SPOTLIGHT virtual audit tool: a valid and reliable tool to assess obesogenic characteristics of the built environment. Int J Health Geogr, 13, 52.

Boessen, A., Hipp, J.R., Butts, C.T., Nagle, N.N., \& Smith, E.J. (2017). Social fabric and fear of crime: Considering spatial location and time of day. Social Networks, 51, 60-72.

Chaix, B., Kestens, Y., Duncan, D., Brondeel, R., Méline, J., El Aarbaoui, T., et al. (2016). A GPS-based methodology to analyze environment-health associations at the trip level: case-crossover analyses of built environments and walking, Am. J. Epidemiol., 184, 579-589.

Chum, A., \& O' Campo, P. (2013). Contextual determinants of cardiovascular diseases: overcoming the residential trap by accounting for non-residential context and duration of exposure. Health Place, 24, 73-79.

Crang, M. (2012). Temporal ecologies: multiple times, multiple spaces, and complicating space times. Environment and Planning A, 44, $2119-2123$.

Cummins, S. (2007). Commentary: investigating neighbourhood effects on health-avoiding the 'local trap'. International Journal of Epidemiology, 36, 355-357.

Elliott, A. (2016). My daughters sleeping patterns for the first 4 months of her life. https://www.reddit.com/r/dataisbeautiful/comments/5l39mu/my daughters sleeping patterns for the first 4/, 2016, 30th December

Fosset, P., Andre-Poyaud, I., Banos, A., Beck, E., Chardonnel, S., Conesa, A., et al. (2016). Exploring IntraUrban Accessibility and Impacts of Pollution Policies with an Agent-Based Simulation Platform: GaMiroD. Systems, 4.

Géographie-cités (2017). Mobiliscope - Cities around the clock. http://mobiliscope.parisgeo.cnrs.fr/.

Inagami, S., Cohen, D.A., \& Finch, B.K. (2007). Non-residential neighborhood exposures suppress neighborhood effects on self-rated health. Social Science \& Medicine, 65, 1779-1791.

Kärrholm, M. (2009). To the rhythm of shopping-on synchronisation in urban landscapes of consumption,. Social \& Cultural Geography, 10, 421-440,.

Kern, L. (2016). Rhythms of gentrification: eventfulness and slow violence in a happening neighbourhood. Cultural Geographies, 23, 441-457.

Kestens, Y., Lebel, A., Chaix, B., Clary, C., Daniel, M., Pampalon, R., et al. (2012). Association between Activity Space Exposure to Food Establishments and Individual Risk of Overweight. PLOS ONE, 7. 
Kimbro, R.T., Sharp, G., \& Denney, J.T. (2017). Home and away: Area socioeconomic disadvantage and obesity risk. Health Place, 44, 94-102.

Kontokosta, C., \& Johnson, N. (2017). Urban phenology: Toward a real-time census of the city using Wi-Fi data. Computers, Environment and Urban Systems, 64, 144-153.

Kwan, M.-P. (2012). The uncertain geographic context problem. Annals of the Association of American Geographers, 102, 958-968.

Kwan, M.P. (2013). Beyond Space (As We Knew It): Toward Temporally Integrated Geographies of Segregation, Health, and Accessibility. Annals of the Association of American Geographers, 103, 1078-1086.

Le Roux, G., Vallée, J., \& Commenges, H. (2017). Social segregation around the clock in the Paris region. Journal of Transport Geography, 59, 134-145.

Lefebvre, H. (1992). Éléments de rythmanalyse: introduction à la connaissance des rythmes.

Lekkas, P., Paquet, C., Howard, N.J., \& Daniel, M. (2017a). Illuminating the lifecourse of place in the longitudinal study of neighbourhoods and health. Soc Sci Med, 177, 239-247.

Lekkas, P., Paquet, C., Howard, N.J., \& Daniel, M. (2017b). The lifecourse of place: Looking past paradigms and metaphors to the just nature of place-health - A rejoinder to Andrews'. Soc Sci Med, 175, 215-218.

Lewis, D. (2017). Capturing Complexity. In G.J. Andrews, T. Brown, S. Cummins, B. Greenhough, D. Lewis, \& A. Power (Eds.), Health Geographies: A Critical Introduction pp. 156-173): Wiley-Blackwell.

Liu, Y., Liu, X., Gao, S., Gong, L., Kang, C., Zhi, Y., et al. (2015). Social Sensing: A New Approach to Understanding Our Socioeconomic Environments. Annals of the Association of American Geographers, 105, 512-530.

Macintyre, S., Ellaway, A., \& Cummins, S. (2002). Place effects on health: how can we conceptualise, operationalise and measure them? Soc Sci Med, 55, 125-139.

Martin, D., Cockings, S., \& Leungy, S. (2015). Developing a Flexible Framework for Spatiotemporal Population Modeling. Annals of the Association of American Geographers, 105, 754-772.

Moon, G., Mohan, J., Twigg, L., McGrath, K., \& Pollock, A. (2002). Catching waves: the historical geography of the general practice fundholding initiative in England and Wales. Soc Sci Med, 55, 2201-2213.

Neutens, T., Schwanen, T., Witlox, F., \& de Maeyer, P. (2010). Evaluating the Temporal Organization of Public Service Provision Using Space-Time Accessibility Analysis. Urban Geography, 31.

Nuvolati, G. (2003). Resident and Non-resident Populations: Quality of Life, Mobility and Time Policies. The journal of regional analysis and policy, 33, 67-83.

Nyhan, M., Grauwin, S., Britter, R., Misstear, B., McNabola, A., Laden, F., et al. (2016). "Exposure Track"The Impact of Mobile-Device-Based Mobility Patterns on Quantifying Population Exposure to Air Pollution. Environ Sci Technol, 50, 9671-9681.

Openshaw, S. (1984). The Modifiable Areal Unit Problem. UK: Norwich, Geo Books.

Park, Y.M., \& Kwan, M.P. (2016). Individual exposure estimates may be erroneous when spatiotemporal variability of air pollution and human mobility are ignored. Health \& Place, 43, 85-94.

Pearce, J. (2015). Invited commentary: history of place, life course, and health inequalities-historical geographic information systems and epidemiologic research. Am J Epidemiol, 181, 26-29.

Perchoux, C., Chaix, B., Cummins, S., \& Kestens, Y. (2013). Conceptualization and measurement of environmental exposure in epidemiology: Accounting for activity space related to daily mobility. Health \& Place, 21, 86-93.

Perchoux, C., Kestens, Y., Brondeel, R. \& Chaix, B. (2015). Accounting for the daily locations visited in the study of the built environment correlates of recreational walking (the RECORD Cohort Study), Prev. Med. 81, 2015, 142-149. 
Setton, E.M., Keller, C.P., Cloutier-Fisher, D., \& Hystad, P.W. (2008). Spatial variations in estimated chronic exposure to traffic-related air pollution in working populations: a simulation. Int J Health Geogr, 7, 39.

Shareck, M., Frohlich, K.L., \& Kestens, Y. (2014a). Considering daily mobility for a more comprehensive understanding of contextual effects on social inequalities in health: a conceptual proposal. Health Place, 29, 154-160.

Shareck, M., Kestens, Y., \& Frohlich, K.L. (2014b). Moving beyond the residential neighborhood to explore social inequalities in exposure to area-level disadvantage: Results from the Interdisciplinary Study on Inequalities in Smoking. Soc Sci Med, 108, 106-114.

Shareck, M., Kestens, Y., Vallée, J., Datta, G., \& Frohlich, K.L. (2016). The added value of accounting for activity space when examining the association between tobacco retailer availability and smoking among young adults. Tob Control. 25, 406-12.

Sharpe, E.K. (2013). Targeted neighbourhood social policy: a critical analysis. Journal of Policy Research in Tourism, Leisure and Events, 5, 158-171.

Thornton, L.E., Pearce, J.R., \& Kavanagh, A.M. (2011). Using Geographic Information Systems (GIS) to assess the role of the built environment in influencing obesity: a glossary. Int J Behav Nutr Phys Act, 8, 71.

Tunstall, R., \& Lupton, R. (2003). Is targeting deprived areas an effective means to reach poor people? In Centre for Analysis of Social Exclusion (Ed.), CASEpaper. London, UK: London School of Economics and Political Science.

Vallée, J. (2017). Challenges in targeting areas for public action. Target areas at the right place and at the right time. Journal of Epidemiology and Community Health, 71, 945-946.

Vallée, J., Cadot, E., Grillo, F., Parizot, I., \& Chauvin, P. (2010). The combined effects of activity space and neighbourhood of residence on participation in preventive health-care activities: The case of cervical screening in the Paris metropolitan area (France). Health \& Place, 16, 838-852.

Vallée, J., Cadot, E., Roustit, C., Parizot, I., \& Chauvin, P. (2011). The role of daily mobility in mental health inequalities: The interactive influence of activity space and neighbourhood of residence on depression. Social Science \& Medicine, 73, 1133-1144.

Zenk, S.N., Schulz, A.J., Matthews, S.A., Odoms-Young, A., Wilbur, J., Wegrzyn, L., et al. (2011). Activity space environment and dietary and physical activity behaviors: a pilot study. Health \& Place, 17, 1150-1161. 